\title{
Experimental Studies of Roughness by Surface Plastic Deformation on Flat Surfaces
}

\author{
Angel Lengerov \\ Technical University - Sofia, Plovdiv \\ Branch \\ Department of Mechanical Engineering \\ and Technologies \\ Plovdiv, Bulgaria \\ e-mail: anlen@tu-plovdiv.bg
}

\begin{abstract}
The article presents experimental studies of the roughness by surface plastic deformation (SPD) on flat surfaces of steel 45. A dispersion analysis was used to study the influence of various factors on the surface quality. From the experimental studies and the dispersion analysis made, a graphical interpretation of the main effects was obtained. Graphical visualizations of the roughness pattern after SPD on the processed surfaces were obtained. Overlapping sinusoidal movements of the deforming spherical element were realized.
\end{abstract}

Keywords-surface plastic deformation, roughness, flat surfaces.

\section{INTRODUCTION}

The loss of machinability of the machine parts usually occurs after the surface layer has been destroyed. It has been found that the functional purpose of various machine-building products depends to a large extent on the qualitative indicators of the surfaces.

One of the simplest and most common methods for controlling a wide range of Surface Layer Quality Parameters is the finishing treatment by surface plastic deformation (SPD).

One of the ways to improve the quality of production is the use of surface plastic deformation processing methods [1]. The advantage of the SPD is a capability to combine effects of finishing and strengthening treatment. In the literature, there is a wide variety of methods for finishing by surface plastic deformation, having a number of specific features [3] - [4]. The most complete and systematic methods for surface elastic deformation are discussed in [2]. In [5] prepared a review of the methods of plastic deformation of matrices and punches.

At the same time, there is no scientifically based methodology allowing the selection of optimal working conditions to ensure the specified quality of the parts.

The purpose of the present work is to perform experimental studies to determine the influence of the geometrical, technological and energetic parameters of the surface plastic deformation on the roughness of the machining surfaces.

\section{General Regulations}

In order to study the influence of the technological parameters of the SPD process on the roughness of the processed surfaces, a number of experimental studies were carried out.

The flat surfaces of steel 45 with chemical composition according to Table 1 are face milling [6]. Sinusoidal overlapping movements with a ball deforming tool have been realized by changing the process parameters of the SPD process.

TABle 1 Chemical Compositionab of Steel 45

\begin{tabular}{|l|l|l|l|l|l|l|}
\hline $\mathbf{C}$ & $\mathbf{S i}$ & $\mathbf{M n}$ & $\mathbf{P}$ & $\mathbf{S}$ & $\mathbf{C r}$ & $\mathbf{N i}$ \\
\hline$\%$ & $\%$ & $\%$ & $\%$ & $\%$ & $\%$ & $\%$ \\
\hline 0,45 & 0,26 & 0,63 & 0,035 & 0,040 & 0,20 & 0,20 \\
\hline
\end{tabular}

The tests were carried out on a drilling machine PB 501. The processed specimens were fastened on the machine table and the ball-forming tool of the vertical spindle The roughness of the specimens after each experiment was measured with a Mitutoyo Surftest - 4 profiles shaper at two lengths, averaging the arithmetic roughness (Fig. 1). A multifactorial dispersion analysis was performed in order to quantify the influence of the factors and regression analysis of the experimental results obtained from the experimental plan.

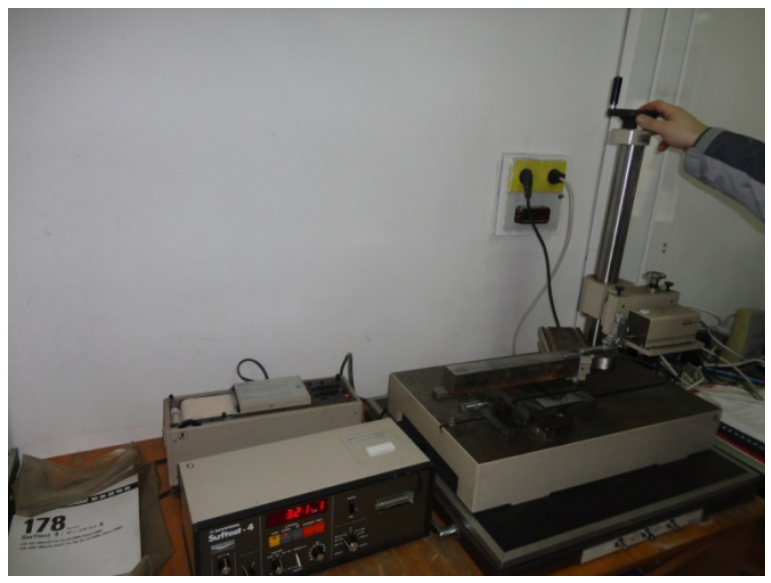

Fig. 1. Roughness measurement.

The levels of variability of the control factors are shown in table. 2 and were selected on the basis of experimental pre-planning results.

Print ISSN 1691-5402

Online ISSN 2256-070X

http://dx.doi.org/10.17770/etr2019vol3.4192

(C) 2019 Angel Lengerov.

Published by Rezekne Academy of Technologies.

This is an open access article under the Creative Commons Attribution 4.0 International License. 
TABLE 2 factors, LeVELS

\begin{tabular}{|c|c|c|c|c|}
\hline Factors & & \multicolumn{3}{|c|}{ Levels of factors } \\
\hline & \multicolumn{3}{|c|}{ coded } & \\
\hline & -1 & $\mathbf{0}$ & +1 & \\
\hline natural & coded & \multicolumn{3}{|c|}{ natural } \\
\hline $\begin{array}{l}\text { Force of pressing of the } \\
\text { ball to the part } \\
F_{b}, N\end{array}$ & $\mathrm{x}_{1}$ & 100 & 300 & 500 \\
\hline $\begin{array}{l}\text { Radius of the } \\
\text { deforming ball tool } r \\
\mathrm{~mm}\end{array}$ & $\mathrm{x}_{2}$ & 5 & 10 & 15 \\
\hline Feed $f, m m / \min$ & $\mathrm{x}_{3}$ & 100 & 900 & 1500 \\
\hline $\begin{array}{l}\text { Number of the cuts } \\
N\end{array}$ & $x_{4}$ & 1 & 2 & 3 \\
\hline $\begin{array}{ll}\text { Initial roughness } \\
R_{a}^{n}, \mu m & \\
\end{array}$ & $x_{5}$ & 1 & 3 & 5 \\
\hline
\end{tabular}

The results of the preliminary experiments show that the models are non-linear. For this reason an optimal composition plan has been chosen.

Since the factors are 5 , the number of experimental points increases to $N=2^{5}+2 \times 5=42$. To reduce attempts, the centre of the plan is chosen to be a fractional replica with $t=3$, that is, the number of attempts in the kernel of the plan is $N_{\ddot{y} a ̈ o ̂}=2^{5-3}=4$. The optimal onepoint composite plan was synthesized by QStatIab [8]. The impact of various factors on surface quality was investigated by dispersion analysis. From the experimental studies and the multifactor dispersion analysis, a graphical interpretation of the major factors was obtained (Fig. 2).

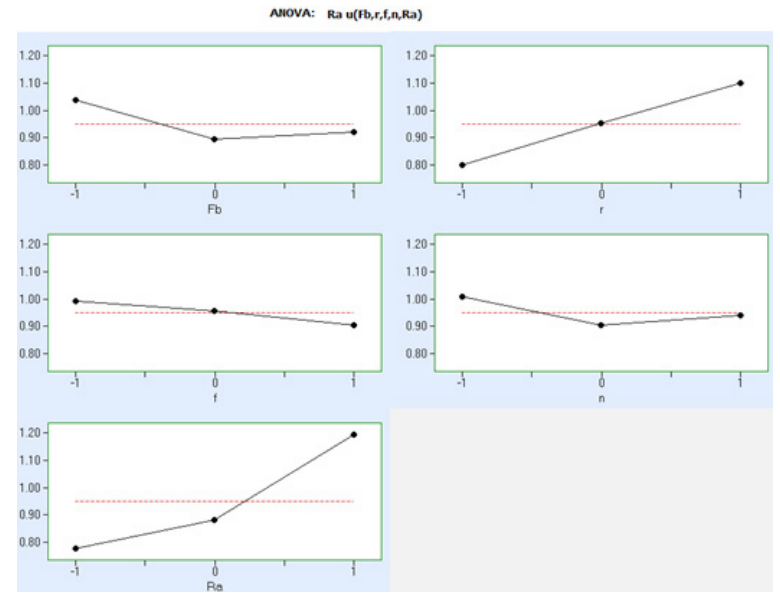

Fig. 2. Overview of the main effects (significance of the factors).

From Fig. 2 it follows that in order to maintain a maximum level of the quality indicator (in this case it is minimal roughness) it is necessary to maintain the 5 factors at the respective levels shown in table. 3. Obviously, reducing the diameter of the ball achieves a reduction in roughness. The impact of the initial roughness is strongest, and the impact of the feed is minimal.

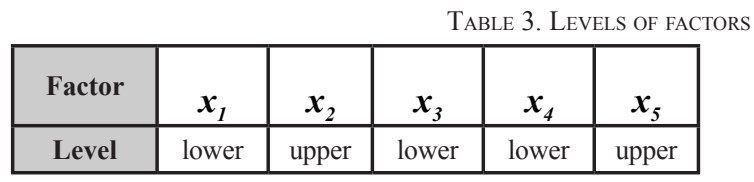

Given the fact that the plan is second order (optimal compositional), the regression model is chosen to be a second order polynomial to allow for a correct statistical analysis [7]:

$$
\begin{aligned}
& Y_{R_{a}}\left(x_{1}, \ldots, x_{6}\right)=b_{0}+\sum_{i=1}^{k} b_{i} x_{i}+\sum_{i=1}^{k-1} \sum_{j=i+1}^{k} b_{i j} x_{i} x_{j}+ \\
& +\sum_{i=1}^{k} b_{i i} x_{i}^{2}
\end{aligned}
$$

where $Y_{R_{a}}$ is the target function of the obtained roughness $R_{a}$ with the arguments of the coded factors.

Coefficients estimates $b_{0}, b_{1}, \ldots, b_{44}, \ldots$ are obtained from the matrix multiplications:

$$
\{b\}=\left([F]^{T}[F]\right)^{-1}[F]^{T}\left\{R_{a, u}\right\},
$$

where $\{b\}$ is the vector of the quoted coefficients in the model, $[F]$ is an extended matrix of the plan, $\left\{R_{a, u}\right\}$ is the vector of the experimental values of the target function $Y_{R_{a}}$.

The resulting regression model is

$Y_{R_{a}}=0.850-0.347 x_{2}+0.302 x_{3}-0.167 x_{5}-$

$-0.122 x_{1} x_{2}+0.648 x_{2}^{2}+0.234 x_{3} x_{5}-$

$-0.475 x_{4}^{2}-0.241 x_{4} x_{5}$

The detailed scan of the obtained model indicates the existence of areas with negative values for the roughness, although the polynomial is of the second degree, and the selected coefficients are significant. For this reason, this roughness model can only be used in area of experimental points to predict roughness, but is not suitable for use in optimization procedures.

The visualization of the main effects (Fig. 3) shows that the influence of the individual factors can be linearized. Based on the plan centre and one central point, the following linear regression model was obtained:

$$
\begin{aligned}
& Y_{R_{a}}=0.952+0.122 x_{1}-0.222 x_{2}+0.26 x_{3}+ \\
& +0.048 x_{4}-0.14 x_{5}+0.079 x_{1} x_{4}+0.07 x_{1} x_{6}- \\
& -0.09 x_{2} x_{3}+0.076 x_{2} x_{4}+0.048 x_{2} x_{5}-0.144 x_{2} x_{5}- \\
& -0.105 x_{3} x_{4}+0.152 x_{3} x_{5}-0.075 x_{4} x_{5}
\end{aligned}
$$

An object of analysis is the model (3).

The relation between encoded (single) $x_{1}$ and natural factors $\%$

$$
x_{1}=\left(\frac{0}{x} 0-\frac{0}{x_{0}, 1}\right) / \lambda_{1},
$$

where

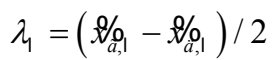




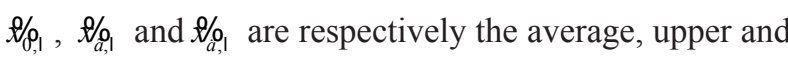
lower levels of the 1 -s natural factor.

After replacing (4) and (5) in (3), the expression of roughness with natural factors is obtained. The results of the analysis are shown in Fig. 3 in the form of threedimensional graphs.
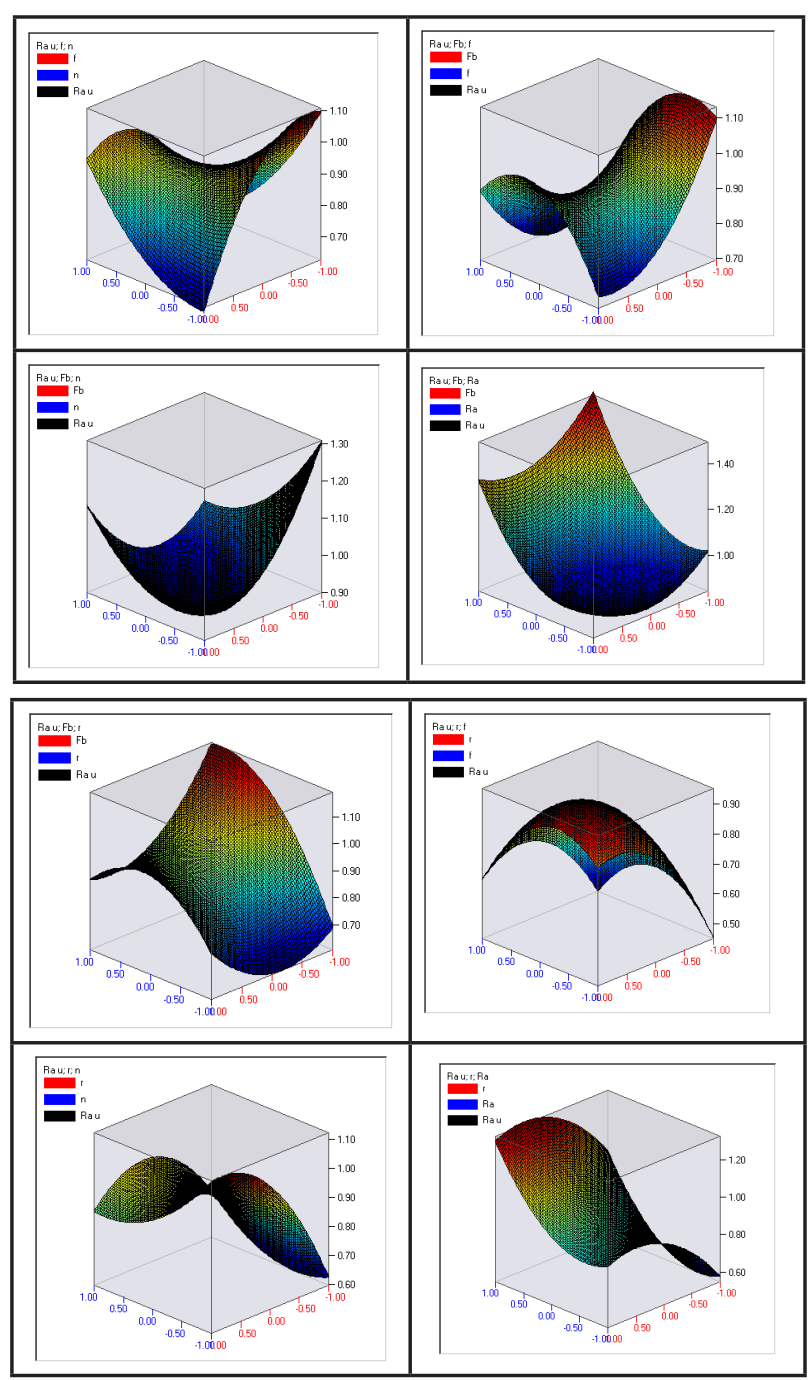

Fig. 3. Three-dimensional graphs of roughness function $Y_{R_{a}}$.

\section{CONCLISIONS}

The resulting graphical visualizations of the roughness pattern model after the SPD of the treated flat surfaces (Fig. 3) confirm the conclusions about the influence, significance and the levels of the factors on the surface qualitative indicators.

The detailed scan of the obtained model indicates the existence of areas with negative values for the roughness, although the polynomial is of the second degree, and the selected coefficients are significant. For this reason, this roughness model can only be used in area of experimental points to predict roughness, but is not suitable for use in optimization procedures.

The implementation of small feeds, a high deformation force and a lower initial roughness lead to an improvement in the qualities of the treated surfaces and greatly reduce the roughness.

\section{REFERENCES}

[1] S N Grigoriev, N M Bobrovskij, P A Melnikov and I N Bobrovskij, "Research of Tool Durability in Surface Plastic Deformation Processing by Burnishing of Steel Without Metalworking Fluids", International Conference on Recent Trends in Physics 2016 (ICRTP2016) IOP Publishing Journal of Physics: Conference Series 7552016011001 doi:10.1088/1742-6596/755/1/011001

[2] L. G. Odintsov ,"Uprochnenie i otdelka detalej poverhnostnym plasticheskim deformirovaniem", Spravochnik [Hardening and finishing details by surface plastic deformation. Handbook] / L. G. Odintsov. M.: Mashinostroenie, 1987. 328 p. [in Russian].

[3] T. Kuzmanov, I. Amudzhev, S. Taneva, "Tool equipment for mechanical surface treatment of small holes", Journal of Machine Building and Machine Science, Varna, Bulgaria, Year. V, No. 2, Vol. 11, pp. 15-18, 2010

[4] T. Kuzmanov, R. Rachev, S. Taneva, K. Ambarev, "Finishing processing of cylindrical rack-wheels for the transport technique by surface plastic deformation", Journal of Fundamental Sciences and Applications, Plovdiv, Bulgaria, Vol.15, pp. 311- 317, 2009.

[5] A.Y. Lavrentev, E.A. Sursimov, "The application of surface plastic deformation for finishing tunching tools", Международный научно-исследовательский журнал - № 9 (51) - Часть 2 Сентябрь, стр.55-57, 2016 DOI: 10.18454/IRJ.2227-6017.

[6] T. KALDASHEV, P. HADZHIYSKI, G. I. Nikolcheva, "Study wear tool with high-speed milling", Environment. Technology. Resources. 11th International Scientific and Practical Conference, June, 2017, 3, pp. 117-121 DOI: 10.17770/etr2017vol3.2598.

[7] Ronald Christensen, "Analysis of Variance, Design, and Regression: Applied Statistical Methods", Chapman and Hall/CRC; 2 edition (December22,2015), 636 pages ISBN-10: 1498730140, ISBN-13: 978-1498730143.

[8] И. Н. Вучков, И. И. Вучков, "Програмен продукт QStatLab Professional, версия 5.4. Рьководство за потребителя”, София, 2009. 